\title{
Study on the Organizational Structure of Rural Land Stock Cooperative System based on Game Theory and Network Data
}

\author{
Liang Xiao \\ School of economics and management, Suzhou University, Suzhou city, Anhui \\ province, 234000, China
}

\begin{abstract}
With the development of economy and society, the agricultural land stock cooperation system is a typical system innovation, which has a significant effect on rural production efficiency. In this paper, we research on the organizational structure of rural land stock cooperative system based on game theory; the result shows that the economic performance of land circulation stock cooperative system is much higher than other land transfer mode. At the same time, the mode of joint-stock cooperative system also has high social performance. By using game theory, we find that farmers tend to passively accept unfair treatment in enterprises based on the consideration of individual benefit, so that governments should effectively implement the macro management functions, and make punishment for the behavior of the enterprise managers' untrue disclosure. In order to improve the agricultural land stock cooperation system, the government should make clear the property right of farmland; promote the scale management of agricultural land and enhance the industrialization of rural areas.
\end{abstract}

Keywords: Rural land circulation; Stock Corporation; Scale operation; Empirical analysis

\section{Introduction}

The rural land stock cooperative system is the reform and innovation of the rural land property rights system in China, and it is a kind of land circulation mode which is explored in practice. With continuous reform to speed up the pace of structural adjustment in agriculture and land scale operation system, rural land joint-stock cooperation system in Guangdong, Fujian and other coastal developed areas of continuous expansion, the central and western regions and remote rural areas also has launched various forms of rural land stock cooperative system in the pilot, and achieved certain results. The share cooperation of rural land, is a typical induced institutional change, can overcome the current land collective all, average household contract management ills, showed obvious social effect, and also becomes a hot issue in theoretical circles[1]. As a new type of system, the rural land joint-stock cooperation system in the implementation process exists many problems, such as unclear property right structure, shares of the right to the contracted management of rural land valuation is not scientific, income distribution system is not standardized, risk prevention mechanism is not perfect and related supporting system construction lag and so on. This has a direct impact on the rural land joint-stock cooperative system performance into full play.

The rural land joint-stock cooperation system is the reform and innovation of the rural land property rights system in our country, overcome the rental, transfer, subcontract, and the limitations of the land transfer in the form of, and it is in practice to explore a new land transfer mode, promote land use rights transfer mechanism of continuous improvement[2]. The rural land joint-stock cooperation system is a in the form of value of the shares instead of the physical form of land transfer of agricultural land system arrangement, and is a sow the land circulation, configure the system to explore. The rural 
land stock cooperative system has promoted the balance development of the interests of the farmers, the collective organizations, the main body of the enterprises and local governments. As a farmer, the transfer of land management right change ownership of rural land joint-stock cooperative enterprises, in addition to directly share shareholder dividends income can also be obtained in the enterprise workers wage income; as farmland joint-stock cooperative enterprises, can save the cost of land acquisition, to obtain sufficient labor resources; as a government, in the land scale of operation, reducing the negotiation cost and scattered farmers, improve administrative efficiency, and promote the sound development of the local economy. The share cooperation of rural land for a typical induced institutional change, can overcome the current land collective all, average household contract management ills, showed obvious social effect, become a hot issue in the theoretical circles.

The development of rural land stock cooperative system is the innovation of land use system, which adapt to the law of the development of market economy, truly realize the clear ownership, stability of the right to contract, enliven the management right, usufruct based protection, the farmers' land contract management rights of property right protection [3]. Therefore, this study have conducive to safeguarding the rights and interests of farmers' legitimate land, promote the increase of farmers' income; is conducive to optimizing the allocation of land resources, increasing agricultural productivity; is conducive to standardizing the land transfer, achieve land intensive management and scale of operation, improve the land productivity; is conducive to the realization of the industrialization of agriculture, the scale of development and modernization, optimize rural industrial structure. In addition, the establishment of rural land joint-stock cooperation system and standardizing operation framework, and proposed further promote the land share cooperation system related measures and policy recommendations, will provide theoretical guidance for the practice of the rural land jointstock cooperation system, for the relevant departments of the government's policy formulation to provide the decision-making reference. Therefore, the research on the development of the agricultural stock cooperative system in our country at present is of great practical significance.

\section{Literature Review}

\subsection{Rural Stock Cooperative System}

When studying the organizational form of enterprises, the foreign scholars usually only have the identification with company system, the partnership and the individual owner, but have not the share cooperation system. Therefore, foreign literature specialized for rural land joint-stock cooperation system of little, almost no books devoted to the study of joint-stock cooperative system, while the vast most of the literature focuses on the research on the theory and practice of economic cooperation[4]. Even so, there are still some foreign scholars in the study of relevant issues, involving the study of China's rural joint-stock cooperative system. China's rural stock cooperative system is a kind of organization with multiple stakeholders, and it has a special research on it. In research cooperation of this kind of enterprise organization form, as a case, has carried on the comparative study of multi angle cooperation organizations in China's rural share cooperation system and other countries and regions, and to explore the different stakeholders in the right. In the face of fierce market competition, some scholars have put forward the improvement measures for the development of cooperatives. Such as Buchanan, Demsetz and other scholars from the clear property rights, restrictions on the number of quasi public goods and other aspects of the improvement, to explore the sustainable development of cooperatives[5]. In the cooperative, the stakeholders can achieve the stable cooperative solution, but there is an important premise is that we must 
adhere to the principle of sharing the interests and share the responsibility in the cooperatives. In order to stimulate the enthusiasm of enterprise employees, improve the traditional labor relations, some foreign companies continue to try to introduce cooperative system factors, such as employee stock ownership.

In the form of property rights, enterprise employees can have the shares of enterprises in any proportion. In employee stock ownership enterprises, with less equity enterprise workers has a wide range of management right, or have widespread ownership of the workers, but lack of decision-making participation rights; in the distribution of profits, not necessarily to equity based, but there is dividends on shares to employees working in limit or labor with dividends and other forms. In short, joint-stock and cooperation of the two forms of enterprise organization and fusion of the practice show that joint stock system and the cooperation system, a variety of independent form of enterprise organization in the development process of the boundaries between is insurmountable.

Although at present abroad without the use of a uniform and specific name of this phenomenon are described and summarized, but in practice is to solve the problems existing in their corporate governance structure in some extent mutual fusion, has become a new direction for the development of a variety of independent form of business organization. Farmers in agricultural production in a large number of specialized investment (such as manual skills, agricultural machinery and so on), agricultural management is facing many uncertainties, and will be subject to geographical conditions. Therefore, the transaction costs of farmers' independent transaction are higher. If you have a trading partner, the transaction costs will be greatly reduced. Vande (2015) research shows that the social factors of cooperative organization operation is also very important[6], cooperation among its members trust, mutual understanding, common value view will make them in many ways, the enterprise policy with consistency, and thus will have lower transaction costs. Rudel(2014) believes that when the economy is facing a declining average cost curve of a non - balanced market relationship, or that the cost of trading with an independent trading partner is too high, the organization will be set up[7].

Interpretation of the enterprise system is also an important application areas of property rights. People will because of the potential cost of incentive to take action improvement possible externalities, internalization of earnings results and the cost of internal and external results are compared, the former than the latter, by setting the property to enable the externality, internalization[8-9]. To sum up, the research on agricultural cooperative economy and stock cooperation system is a hot spot of foreign scholars' research. In practice, along with the development of capitalist economy, the cooperative economy has more and more influence in the agricultural field of each country, and the thought and practice of the agricultural cooperative economy is also expanding and deepening. Theoretically, the contribution of the new institutional economic scholars to the cooperative economic system is the most prominent. The practical experience of foreign rural cooperative economy and the theory, methods and research perspective of foreign scholars' research on cooperative economy in China provide important reference and inspiration for the study of China's rural land stock cooperative system.

\subsection{Agricultural Cooperative Economy}

Neo classical economic school has not been the enterprise system as its research object. Research on agricultural cooperatives is mainly concentrated in the twentieth Century years after the. Economists in the new classical economic school regarded cooperatives as a kind of good enterprise system, which can improve the market competition advantage, scale economy and promote social and economic welfare. The main views on the nature of cooperatives are the extension of the farm, independent manufacturers, and joint manufacturer's three categories. Whether from economic or non economic point of view compared to other systems, in terms of institutional superiority and institutional efficiency, cooperative or employee sharing system is higher than other systems. Different from the 
traditional new classical economics, the new institutional economics mainly use property rights theory, transaction cost theory, game theory and principal-agent theory to study the cooperative economy. Such as property economists, because it was not clearly defined ownership, will inevitably lead to low efficiency of cooperative organizations; and then from the perspective of agency theory to analyze the distribution, think there is inefficient, inefficient and inefficient scale technology cooperation organization, results in a significant increase in the cost of agency; fuzzy property organization and transaction cost is high, the organization, many the problems of investment combination, public ownership, especially when the structure of cooperative organization is more and more complex, these issues are particularly prominent; also use the property right theory to analyze the cooperation organization, also proposed should establish a cooperative organization[10]. From the perspective of the theory of transaction cost analysis, the agricultural cooperative economic organizations can effectively avoid the market risk and nature to enable enterprises to reduce transaction costs. By the time of the twentieth Century, the methods of the theory and mathematical model were adopted, which made the research of cooperative economic theory more scientific. Such as uses contract theory to construct a in cooperatives organized screening model and the bargaining model, established on the investment decision model of game theory; and respectively using incomplete contract theory and transaction cost theory of agricultural marketing cooperatives in agricultural marketing cooperatives and investment constraints and control constraints between relationship; and use of microeconomics, voting theory, industrial organization theory, agricultural marketing cooperative investment decisionmaking model is established, and the development of competition model in duopoly market cooperatives and between.

Although the cooperatives to strengthen the reciprocal cooperation between producers and traders, reduce transaction costs, however, with the further development of market economy in capitalism, the traditional cooperative gradually appeared shortage of funds, efficiency of slow growth, members "hitchhike", management lags behind etc. a series of problems. The contradiction between the modern market economy and the cooperatives is increasing day by day. Some western developed countries to break through the existing cooperative framework, the introduction of the practice of some joint-stock enterprises, or directly into the shareholding system. Economic development of western countries jointstock cooperation tendency started after the 1960s, which carried out in the interior of the shares of the company ESOP [11]. ESOP is incorporate some of the cooperation system factors in joint-stock enterprises, enterprise to be given priority to with the employee stock ownership, namely enterprise all right to return all the workers, the workers elected Management Committee is the highest organ of power, the Management Committee for the appointment of manager is responsible for the operation and management of the enterprise, the enterprise decision stressed members voting mechanism, and take "according to distribution according to work" and "dividends on shares" combining income distribution. To sum up, the research on agricultural cooperative economy and stock cooperation system is a hot spot of foreign scholars' research. In practice, along with the development of capitalist economy, the cooperative economy has more and more influence in the agricultural field of each country, and the thought and practice of the agricultural cooperative economy is also expanding and deepening. Theoretically, the contribution of the new institutional economic scholars to the cooperative economic system is the most prominent. The practical experience of foreign rural cooperative economy and the theory, methods and research perspective of foreign scholars' research on cooperative economy in China provide important reference and inspiration for the study of China's rural land stock cooperative system. 


\section{Innovation of Rural Land Transfer Mode}

\subsection{Rural Land Stock Cooperative System}

Because the rural land stock cooperative system has the characteristics of practice and theory behind, there is no uniform definition and model. The research object of this paper is the rural land stock cooperative system in rural contracted land management as the main content of the joint-stock cooperative, is in accordance with the principle of voluntary farmers, based on the collective land ownership, stable household contract rights, enliven the land management right, initiated by the large, the economic strength of the collective economic organization or invest in agricultural enterprises, farmers contracted land or collective land, combined with capital, equipment and technology and other production factors to quantify shareholder, land or other production factors specific business by a joint-stock cooperative organization unified enterprise management, business profits after deducting the necessary according to shares dividends, thereby establishing a sharing of benefits and risks of stock cooperative system. The rural land joint-stock cooperation system is in the clear land collective ownership, stable household contract rights and liberalize the countryside land use rights based, the shareholding system is introduced into the field of agricultural production, land use rights shares, cooperation of rural land circulation management mechanism, is set in the interests of farmers, the collective and the enterprise, the national multi subject to one of a balanced mechanism, is due to the land value-added income induced by a transitional institutional arrangement. The farmland stock cooperation system is explored in practice, a kind of land transfer mode, a in the form of value of the shares instead of the physical form of land transfer system arrangement, and is a land transfer, configure the system to explore. Farmland shareholding cooperative system, farmers still have the household contract on the basis of the right to the contracted management of land, farmers in land real right to the contracted management of land has not changed, on the basis of land ownership and the right to the contracted management of two rights separation, the realization of the rural land contracting right and operation right separation.

Rural land joint stock cooperative enterprise is a kind of cooperative economic organization. In clear the rural collective land ownership, stable household contract rights, deregulation of land use rights based, initiated by the economic strength of large, the collective economic organizations or investment in agricultural industrial and commercial enterprises, the farmers contracted land or collective all land, combined capital, equipment, technology and other production factors to quantify shareholder, in accordance with the principle of voluntary, composed of benefit sharing, risk sharing of joint-stock cooperative system of agricultural enterprises. The rural land stock cooperative enterprise is a new type of cooperative economic organization, which is based on the principle of adhering to the basic principle of cooperative system, and absorbs the factors such as stock ownership. The main modes of rural land stock cooperation system are:

1) Whether the farmers directly participate in the joint stock cooperation: one kind is the circulation mode of the share cooperation system. In the model, rural land transfer, not directly involved in the land stock cooperation management, principle shares land price and land shares after cooperation organization integration, unified publicly leasing, rental income of income by farmers land ownership share distribution. The risk is small, the operation is simple, mainly in the second and the third industry developed rapidly, agricultural production does not occupy dominant position, most of the peasant labor or transferred to other industries or unwilling to continue to 
engage in agricultural production and operation areas. The second is the joint stock cooperative system. In this model, the rural land transfer, directly involved in the operation and management of the land stock cooperation, farmers to land contractual management right discount shares and the absorption of equity capital and technology, the establishment of a joint stock cooperatives or cooperative joint-stock enterprises, unified management, farmers in land shares to participate in the distribution of benefits.

2) Elements of the shares to classify: pure land ownership shares of land shareholding cooperative system transfer mode. Revenue of general shares by a single farmer land formed land joint-stock cooperative enterprises, cooperatives to land ownership as the operating target, unified to lease or contract, made by farmers land into the share allocation, land ownership can be both farmers contracted land can also be collective non-agricultural construction land. Simple land stock cooperatives can be set up by the village group as a unit, but also to the village as a unit or cross community. The model suitable in traditional agricultural area, because a small business difficult to achieve unifinication of trade workers and peasants is not conducive to intensive management of agriculture, it is difficult to obtain ideal scale benefit. Therefore, we can rely on leading products, leading industries, the land contracted to professional large or agricultural enterprises, the development of high-quality and efficient agriculture, and promote land efficiency and increase farmers' income. At the same time, the model also apply in the rapid advance of industrialization of suburban and rural areas, in these areas, agriculture is relatively low income, most of the labor force the shift to the secondary and tertiary industries, land joint-stock cooperation can not only solve the extensive management of land or abandoned, and enable the farmers to obtain a stable job and income, but also to protect the rights and interests of farmers' land contract.

\subsection{Comparative advantage of share cooperative system}

Traditional land subcontract, rent a bale instead, leasing, trust, replacement, back pack, mortgage, seasonal subcontract or lease, use right auction, and the stock cooperation, etc. form, to improve land use efficiency, optimize the allocation of agricultural factors of production, increase the income of the farmers, developing the modern agriculture and plays an important role, resulting in a good economic and social benefits. Based on the land productivity model, the comprehensive evaluation index of the rural land transfer mode is calculated.

$$
\mathrm{A}=\varphi \beta /(1-\gamma) \cdot(C+w+\alpha)+\delta \cdot \varphi /(1-\gamma) \cdot(C+\alpha)
$$

In this formula, $\varphi$ means unit of land output rate index, $\beta$ as land circulation scale benefit index, $\gamma$ is the technology cost index, $C$ as a new variety regeneration index, $\mathrm{w}$ as outward investment affects the index, $\alpha$ as domestic start index, $\delta$ as workforce by index. According to the comprehensive evaluation model of labor utility, the basic formula of comprehensive evaluation index of social performance as:

$$
\mathrm{Q}=s \cdot(1+X) \cdot(\mu+\tau+\psi+\eta)
$$

$\mathrm{S}$ means the farmers in the land circulation on the employment index selection for farmers, $\mu$ as skills transfer index, $\tau$ as farmers' social participation index. $\psi$ as farmers rights law index, $\eta$ as farmers market competitiveness index, $X$ as activation index owned capital for farmers. According to the above calculation 
formula, according to the survey and statistics, analysis of the land transfer of the economic performance of the composite index and social performance index, the following results, as shown in table 1 , table 2

Table 1. Economic Performance Composite of Different Land Transfer

\begin{tabular}{|c|c|c|c|c|c|c|c|c|}
\hline Land transfer mode & $\beta$ & $\gamma$ & $\varphi$ & $\mathrm{C}$ & $\mathrm{w}$ & $\alpha$ & $\delta$ & $\mathrm{Q} \%$ \\
\hline subcontract & 0.3 & 0 & 0.2 & 0.5 & 0.5 & 0 & 0 & 6.0 \\
\hline Anti rent & 0.5 & 0 & 0.3 & 0.8 & 0.5 & 0 & 0 & 19.5 \\
\hline Joint stock cooperation & 0.8 & 0.5 & 0.5 & 0.4 & 0.5 & 0.5 & 0.8 & 50.61 \\
\hline lease & 0.25 & 0 & 0.2 & 0.5 & 0.3 & 0.1 & 0 & 4.5 \\
\hline trust & 0.35 & 0 & 0.1 & 0.5 & 0.3 & 0.1 & 0 & 3.15 \\
\hline substitution & 0.2 & 0 & 0.1 & 0 & 0 & 0.2 & 1.0 & 2.4 \\
\hline Seasonal subcontract & 0.25 & 0 & 0.1 & 0.4 & 0.3 & 0 & 0.6 & 4.15 \\
\hline auction & 0.5 & 0 & 0.3 & 0.4 & 1.0 & 0.1 & 0 & 22.5 \\
\hline mortgage & 0.35 & 0 & 0.2 & 0.5 & 0.7 & 0.1 & 0 & 9.1 \\
\hline
\end{tabular}

Table 2. Social Performance Composite of Different Land Transfer

\begin{tabular}{|c|c|c|c|c|c|c|c|}
\hline Land transfer mode & $\mathrm{s}$ & $\mu$ & $\tau$ & $\psi$ & $\eta$ & $\mathrm{x}$ & $\mathrm{Q} \%$ \\
\hline subcontract & 0.3 & 0 & 0.5 & 0.5 & 0.9 & 0 & 27 \\
\hline Anti rent & 0.2 & 0 & 0.2 & 0.5 & 0.4 & 0 & 22 \\
\hline Joint stock cooperation & 0.5 & 0.5 & 0.4 & 0.4 & 0.6 & 0.5 & 142.5 \\
\hline lease & 0.3 & 0 & 0.5 & 0.3 & 0.3 & 0.1 & 36.3 \\
\hline trust & 0.4 & 0 & 0.2 & 0.5 & 0.5 & 0.4 & 67.2 \\
\hline substitution & 0.2 & 0.3 & 0.2 & 0.2 & 0.2 & 0.3 & 15.6 \\
\hline Seasonal subcontract & 0.2 & 0.5 & 0.3 & 0.3 & 0.8 & 0.4 & 71.4 \\
\hline auction & 0.4 & 0 & 0.2 & 0.5 & 0.9 & 0.1 & 70.4 \\
\hline mortgage & 0.4 & 0 & 0.3 & 0.5 & 0.9 & 0.1 & 74.8 \\
\hline
\end{tabular}

\section{Empirical Analysis}

\subsection{Stakeholders}

The related interest subjects of rural land stock cooperation system are mainly farmers, rural land shareholding cooperative enterprises or organizations, as well as village collective organizations and local governments. As a farmer, through shares of rural land use rights to land shares in addition to the direct share of revenue, but also in the employment of the stock cooperative system of rural land, or in migrant workers, increase wages; as the rural land joint-stock cooperative enterprises, first saves the business required land acquisition costs, and you can get plenty of local labor resources, lay a foundation for the material and human resources to improve business efficiency; as a local government, on the one hand caused by the share cooperative system of rural land circulation of land scale production and industrialization, has brought great economic benefits and social benefits, on the other hand, the local government and enterprises the rural land joint-stock cooperative negotiation, reduce the cost and to negotiate the dispersed farmers, land acquisition process is greatly simplified and shortened, supervision efficiency and administrative efficiency The rate has also been greatly improved. Based on the above analysis, the circulation of rural land stock cooperative system makes farmers, rural land joint-stock cooperative enterprises and local governments and other multiple stakeholders to achieve a win-win situation. 


\subsection{Game Analysis of Farmer and Enterprise Managers}

The most common game behavior in the rural land stock cooperative system is the game between the farmers and the rural land stock cooperative enterprises. For the establishment of game model, the basic assumption for the condition as follows: $\mathrm{N}$ on behalf of farmers, $\mathrm{J}$ represents the rural land joint-stock cooperative enterprises operators; $\mathrm{N}$ and $\mathrm{J}$ to rational economic man, namely in a limited range is the pursuit of profit maximization; game model of information is flowing freely.

According to the above assumptions, N's strategy choice can have two kinds: join or not join, J's strategy choice also has two kinds: the true disclosure of information or not true disclosure of information. Thus, there are four possible combinations of strategies between $\mathrm{N}$ and $\mathrm{J}$.

1) If $\mathrm{J}$ true disclosure of information, $\mathrm{N}$ accession, the two sides have the income of $\mathrm{P} 2$;

2) J does not disclose the true information, get $\mathrm{P} 1$ income; $\mathrm{N}$ to join, get $\mathrm{P} 3$ income,

3) $\mathrm{J}$ true disclosure of information, the income of $\mathrm{P} 2$; $\mathrm{N}$ does not join, get $\mathrm{P} 4$ income,;

4) $\mathrm{J}$ does not disclose the true information, $\mathrm{N}$ does not join, and the two sides have the income of $\mathrm{P} 3$.

Table 3. Two Matrix Game Model for Farmers

\begin{tabular}{|c|c|c|c|}
\hline \multicolumn{2}{|c|}{ Game matrix } & \multicolumn{2}{c|}{ J (enterprise operators) } \\
\cline { 3 - 4 } & Join & Real disclosure & Unreal disclosure \\
\hline \multirow{2}{*}{$\mathrm{N}$ (farmers) } & Not join & $(\mathrm{P} 2, \mathrm{P} 2)$ & $(\mathrm{P} 4, \mathrm{P} 1)$ \\
\cline { 2 - 4 } & & $(\mathrm{P} 3, \mathrm{P} 1)$ & $(\mathrm{P} 3, \mathrm{P} 3)$ \\
\hline
\end{tabular}

From table 3, we can see that the first choice between farmers and rural land stock cooperative enterprises, the behavior of the state is conducive to the normal circulation of rural land stock cooperative system. But in the rural land joint-stock cooperation system transfer process, the operator's strategy selection will tend to be unreal disclosure of relevant information, harm farmer interest, farmers the best strategy choice to join, in this case, both sides get income (P3, P3), Nash equilibrium is achieved, both sides in the game will also be in a stable, and will keep for a long time. Therefore, the status of rural land stock cooperation system is difficult to carry out the transfer, the rural land joint-stock cooperative enterprises difficult to raise land or capital and other factors of production, farmers' land or funds are not fully and effectively utilized.

But real equilibrium strategy (P1, P4), because farmers hope their own land or capital and other factors of production can be fully utilized, make the final "join" selection method, become the rural land stock cooperation system enterprise operators unreal disclosure related information to be the biggest victims. To get rid of this unfair behavior game "dilemma", local government effectively implement macro management functions, of rural land stock cooperation system enterprise operators' unreal disclosure of relevant information behavior to punish. Hypothesis of rural land stock cooperation system enterprise operators are not true disclosure related information to act by the punishment for $\mathrm{D}$, farmers and rural land joint-stock cooperation system enterprise operators matrix game model of the extended model is established. As shown in the table. 
Table 4. Extended Model of Two Matrix Game

\begin{tabular}{|c|c|c|c|}
\hline \multicolumn{2}{|c|}{ Game matrix } & \multicolumn{2}{c|}{ J (enterprise operators) } \\
\cline { 2 - 4 } & Join & Real disclosure & Unreal disclosure \\
\hline \multirow{2}{*}{$\mathrm{N}$ (farmers) } & Not join & $(\mathrm{P} 2, \mathrm{P} 2)$ & $(\mathrm{P} 4, \mathrm{P} 1-\mathrm{D})$ \\
\cline { 2 - 4 } & & $(\mathrm{P} 3, \mathrm{P} 1)$ & $(\mathrm{P} 3, \mathrm{P} 3-\mathrm{D})$ \\
\hline
\end{tabular}

From table 4 shows, if the rural land stock cooperation system enterprise operators unreal disclosure of relevant information, will be punished, rural land joint-stock cooperative enterprises damaged the image and affect the subsequent operation, resulting in a profit decline, or even a loss, at this time, the return value is P1-D. But due to the timely intervention of local government regulatory authorities, forcing the rural land stock cooperation system enterprise operators the true disclosure of relevant information, farmers to make a decision to join, make policy becomes a ideal Nash equilibrium. At this time both benefits for $(\mathrm{P} 2, \mathrm{P} 2)$ to reach the equilibrium point.

From this game shows that, in the short term, rural land joint-stock cooperative enterprise operators unreal disclosure related information or perhaps get a higher income, but in the long run, rural land joint-stock cooperative enterprises to sustained and stable development, access to long-term interests must be true disclosure related information, to maximize the economic and social effects. Only in this way, the transfer of rural land stock cooperative system can be carried out smoothly and effectively.

\subsection{Game Analysis of Regulators and Enterprise Managers}

The local government in order to guarantee rural land joint-stock cooperation system circulation normal, farmers interests will not be harmed, will specify the relevant regulatory authorities of rural land joint-stock cooperative enterprises founded and operation of supervision and management. In order to establish the supervision game model between the supervision department and the rural land stock cooperative system, the basic assumptions are as follows:

1) Agricultural land stock cooperative enterprise J, Supervision department Z, Both sides know their income and payment and game structure

2) Pure strategy of rural land joint-stock cooperative enterprises: false or false. The hypothesis that $\mathrm{A}$ is revenues for fake, - $\mathrm{A}$ is revenues for non-fake, $\mathrm{F}$ is the punishment

3) The pure strategy of the supervision department is: check or not check. $\mathrm{C}$ is regulatory costs for the regulatory authorities

4) Assuming that the land joint-stock cooperative enterprises fraud, supervision department supervision, then there exists a: someone reported or implicated in the crime, not only the false of cooperative joint-stock enterprises were punished, regulatory authorities be held responsibility at the same time has also been punished D 
Table 3. Two Matrix Game Model for Farmers

\begin{tabular}{|c|c|c|c|c|c|}
\hline \multicolumn{2}{|c|}{ Game matrix } & \multicolumn{4}{c|}{ Z (regulators) } \\
\cline { 3 - 6 } & Find & Not fimd & report & Not report \\
\hline \multirow{2}{*}{$\mathrm{J}$ (enterprise operators) } & Fraud & $(-\mathrm{F}, \mathrm{F}-\mathrm{C})$ & $(\mathrm{A},-\mathrm{C})$ & $(\mathrm{A}-\mathrm{F},-\mathrm{D})$ & $(\mathrm{A}, \mathrm{C}-\mathrm{A})$ \\
\cline { 2 - 6 } & No fraud & $(-\mathrm{A},-\mathrm{C})$ & $(-\mathrm{A},-\mathrm{C})$ & $(-\mathrm{A}, \mathrm{C})$ & $(-\mathrm{A}, \mathrm{C})$ \\
\hline
\end{tabular}

As can be seen from table 5, there is no dominant strategy equilibrium and pure strategy Nash equilibrium in this game model. Therefore, it is necessary to make more close to the actual assumptions of various uncertain factors in the static game of incomplete information, to solve the Nash equilibrium of the mixed strategy. Suppose $\mathrm{P}$ for the false probability of rural land joint-stock cooperative enterprises; probability q for regulators to supervise; $\mathrm{R}$ for the departments of supervision found false probability; $\mathrm{W}$ supervision department supervision have reported probability.

Under this assumption, the expected benefits of the regulatory authorities, rural land joint-stock cooperative enterprises Q1 and Q2:

$$
\begin{gathered}
\mathrm{Q}_{1}=q \cdot\{r[p(F-C)+(1-P)(-C)]+(1-r)[p(F-C)+(1-P)(-C)]\}+(1-q) . \\
\{w[p(-D)+(1-p) C]+(1-w)[p(-D)+(1-p) C]\} \\
\quad \mathrm{Q}_{2}=p \cdot\{q[r(-F)+(1-r) A]+(1-q)[w(A-F)+(1-w) A]\}+(1-p) A
\end{gathered}
$$

The conditions for the maximum expected return of the supervision departments and the rural land stock cooperative enterprises:

$$
\frac{\partial Q_{1}}{\partial q}=0, \frac{\partial Q_{2}}{\partial p}=0
$$

The mixed strategy Nash equilibrium solution of this game is:

$$
\begin{aligned}
p^{*} & =\frac{2 C}{r F+w(D+C-A)+A} \\
q^{*} & =\frac{2 A-w F}{r(A+F)-w F}
\end{aligned}
$$

From the equilibrium solution can be seen under the conditions established institutional arrangements, regulators and rural land joint-stock cooperative enterprises to maximize the expected return, regulators should be to select the $q^{*}$ probability of supervision, and rural land joint-stock cooperative enterprises should be to select the $\mathrm{p} *$ of the probability of false. Regulators found that rural land joint-stock cooperative enterprises do false probability $\mathrm{R}$ is higher, the penalties $\mathrm{f}$ is greater, and detrimental to the regulatory supervision of punishment $\mathrm{d}$ more, someone to the supervision department supervision report probability $\mathrm{w}$ higher, will lead to the rural land joint-stock cooperation of enterprises false probability $\mathrm{P}$ decreased; but regulatory supervision cost $\mathrm{C}$ is large, will make rural land joint-stock cooperative enterprises false probability p rise.

By the farmers and rural land joint-stock cooperative enterprise operators, rural land joint-stock cooperative enterprise operators and regulators game analysis shows: in the rural land joint-stock cooperation system transfer process, to achieve maximum economic and social benefits must be real, comprehensive and complete disclosure of relevant information on the operation and management. Therefore, to promote the circulation of 
rural land stock cooperative system sound, healthy development, it is necessary to regulate the information disclosure of Rural Land Shareholding Cooperative System in the process of circulation.

\section{Conclusions}

The farmland stock cooperation is a typical induced institutional change, can overcome the current collective land all the drawbacks of the household contract management, compared with other modes of farmland circulation, with obvious innovation performance. To a certain extent, to clarify the property rights of agricultural land, to promote the scale management of agricultural land, to further standardize the transfer of agricultural land, promote the industrialization of the rural management, the formation of land manager's stable expectations. The implementation of joint stock cooperation is not only the innovation of land system, but also the innovation of management system. It is in line with the direction and requirements of the development of the advanced productive forces in the new era.

The governance structure of the rural stock cooperative system refers to a set of institutional arrangements which are related to each other and used to regulate the rights, responsibilities and interests of the owners, owners, managers and other stakeholders in the enterprise legal person. The essence of corporate governance is through the balance of right, responsibility and interests of corporate asset structure to regulate the capital owner and the agent, the agent and the agent mutual interests, it is from enterprise behavior, behavior rules and inter power allocation, supervision, control and coordination, incentive, restriction of economic, legal and moral system arrangement,. Establishing the fundamental purpose of corporate governance is through certain governance structure, making related to assets of various rights in separate state, maintain the effective restriction and supervision; make asset the rights to master and use the strictly by the corresponding asset liability constraints as much as possible to prevent moral hazard, so as to realize the harmonious balance and target of the interests of all parties, in order to improve the enterprise's overall operating efficiency.

\section{Acknowledgments}

The work of this paper is supported by Anhui Province Education Department Key projects of support program for outstanding young talents in Colleges and Universities: "Study on the problem of management in agricultural moderate scale in a new round of land transfer in North Anhui" (No. gxyqZD2016336); Suzhou University professor (PhD) research start-up fund project: "Research and practice of management in agricultural moderate scale in North Anhui" (No. 2015jb10).

\section{References}

[1] C. Urrea-Hernandez, C. J. M. Almekinders and Y. K. Van Dam, "Understanding perceptions of potato seed quality among small-scale farmers in Peruvian highlands", NJAS - Wageningen Journal of Life Sciences, vol. 76, pp. 21-28.

[2] Y, Tang, R. J. Mason, "Governments' functions in the process of integrated consolidation and allocation of rural-urban construction land in China", Journal of Rural Studies, vol. 42, (2015), pp. 43-51.

[3] J. Sok, H. Hogeveen and A. R. W. Elbers, "Farmers' beliefs and voluntary vaccination schemes: Bluetongue in Dutch dairy cattle", Food Policy, vol. 57, (2015), pp. 40-49.

[4] M. Yazdanpanah and F. Feyzabad, "Predicting farmers' water conservation goals and behavior in Iran: A test of social cognitive theory", Land Use Policy, vol. 47, (2015), pp. 401-407.

[5] I. D. Hodge and W. M. Adams, "Property institutions for rural land conservation: Towards a postneoliberal agenda", Journal of Rural Studies, vol. 36, (2014), pp. 453-462.

[6] F. V. Velde and E. Claerebout, "Diagnosis before treatment: Identifying dairy farmers' determinants for the adoption of sustainable practices in gastrointestinal nematode control,Veterinary Parasitology", vol. 212, (2015), pp. 308-317. 
[7] T. K. Rudel and P. Meyfroidt, "Organizing anarchy: The food security-biodiversity-climate crisis and the genesis of rural land use planning in the developing world", Land Use Policy, vol. 36, (2014), pp. 239-247.

[8] C. Bittner and M. Sofer, "Land use changes in the rural-urban fringe: An Israeli case study", Land Use Policy, vol. 33, (2013), pp. 11-19.

[9] E. Kerselaers and E. Rogge, "Changing land use in the countryside: Stakeholders' perception of the ongoing rural planning processes in Flanders", Land Use Policy, vol. 32, (2013), pp. 197-206.

[10] X. B. L. Bravo and C. Hubbard, "What drives farmers' participation in EU agri-environmental schemes?: Results from a qualitative meta-analysis", Environmental Science \& Policy, vol.54, (2015), pp. 1-9.

[11] H. B. Glick and C. Bettigole, "Wyoming's Aging Agricultural Landscape: Demographic Trends Among Farm and Ranch Operators, 1920-2007”, Rangelands, vol. 36, (2014), pp. 7-14. 